\title{
CORRESPONDENCE
}

pediatric patients during mechanical ventilation. Respir Care 1986;31:1188-1196.

3. Demers RR. Bacterial/viral filtration: let the breather beware! (opinions/hypotheses) Chest 2001;120(4):1377-1389.

\section{Is Anything Absolute?}

In Reply:

Mr Demers et al's letter brings up a wonderful discussion about a common method of using an absolute filter to conduct aerosol research. The use of an absolute filter allows for an estimate of the total dose within a given model. Although this is a common method, it has several limitations. Let's start with the definition of absolute filter. Filters often used for aerosol research are off the shelf bacterial/viral filters, because they are easily accessible. Therefore, the characteristics of these filters are based on the smallest bacterial or viral organism typically seen within the respiratory tract. Although a single virus or bacterium can range from 0.01$0.5 \mu \mathrm{m}$, it does not often travel alone, which can make its size larger. ${ }^{1}$ When viruses and bacteria do travel alone, they pose less of a risk due to dilution; this limits the availability and consequently the use of higher efficiency at smaller particle size filters in this arena of research.

The absolute rating of a bacterial or viral filter is the cut-off point at which a filter is capable of efficiently prohibiting the stated particle size or greater. The term "absolute" is used to describe or define the degree of filtration of a particular filter. Efficiency of the absolute filter is then described as a percentage (usually $\geq 95 \%$ ) of a particular size that the filter is capable of filtering and higher. The term absolute in filtration does not mean it will "block $100 \%$ of whatever particles and/or microorganisms by which it is bombarded," as stated in your letter.

The Respirgard II 303 absolute filter is rated at $99.9 \%$ bacterial and 99.8 viral efficiency of $0.3 \mu \mathrm{m}$ or larger-sized particles as measured by the Nelson Laboratory, Inc. (package insert). This information should have been included in our method section, but was mistakenly left out. The Centers for Disease Control and Prevention recommend bacterial and viral filter efficiently at a minimum of $0.3 \mu \mathrm{m}$ at $>95 \%$ efficiency, ${ }^{2}$ so the use of the Respirgard II 303 is common practice at our institution. The Pall filter goes beyond the Centers for Disease Control and Prevention recommendation and filters to $0.20 \mu \mathrm{m}$ and is $99.999 \%$ efficient for both bacterial and viral organisms. So, it is not surprising within your experiment that some smaller particles were captured in the more efficient Pall filter.

When choosing the Respirgard II 303, it was thought the filtration efficiency at $0.3 \mu \mathrm{m}$ was acceptable and $0.1 \mu \mathrm{m}$ smaller than the smallest stage $(0.4 \mu \mathrm{m})$ studied. The filter type and lot number was kept consistent between experiments, allowing us to draw the conclusion within the established methods. Your point is well taken that drug delivery may be actually higher than measured in our study and in favor of the small particle aerosol generator, because it did produce smaller particles than the vibrating mesh micropump produced. You will read that we shied away from drawing conclusions on dosing, because our group feels that clinical trials are needed to measure sputum or serum drug levels between devices to definitively come to those conclusions.

Your semiquantitative test using methylene blue and a flow of $15 \mathrm{~L} / \mathrm{min}$ was not the same method utilized in our study. Methylene blue has a different chemical makeup than the drug we studied; I am unsure of what this chemical makeup difference would do to the mass median aerodynamic diameter performance of the vibrating mesh micropump or the filter behavior. The filters in our experiment were exposed to biphasic flow patterns seen within our pediatric lung model simulation as presented within our study. ${ }^{3}$ The majority of flow during inspiration are well below $15 \mathrm{~L} / \mathrm{min}$. It is well known that filters lose their efficiency at higher flow frequencies. ${ }^{4}$ This means the efficiency of these filters is higher than if we were to use the same filters in an adult lung model simulation and could have come into play within your experiment. Although visually convincing, I'm not sure any conclusion can be developed other than to say that the Pall filters very efficiently and to a smaller particle size. This could have been determined by efficiency comparisons.

In summary, I am very thankful for Demers et al's letter. Especially for including a student in our professional dialogue. The term absolute can be misleading to clinicians, but I believe it had little influence on the results of our study. More importantly, no absolute filter is $100 \%$ efficient, and I echo the message that caregivers need to mount appropriate precautions to limit exposure to potentially harmful aerosols. This includes understanding the manufacturer's recommendations for use and not deviating from those recommendations. I have always embraced practices of appropriate filtering of equipment and personnel.

Brian K Walsh PhD RRT-NPS FAARC Boston Children's Hospital Harvard Medical School Boston, Massachusetts

The author has disclosed no conflicts interest.

DOI: $10.4187 /$ respcare. 05333

\section{REFERENCES}

1. Verreault D, Moineau S, Duchaine C. Methods for sampling of airborne viruses. Microbiol Mol Biol Rev 2008;72(3):413-444.

2. Jensen PA, Lambert LA, Iademarco MF, Ridzon R; Centers for Disease Control and Prevention. Guidelines for preventing the transmission of Mycobacterium tuberculosis in health-care settings, 2005. MMWR Recomm Rep 2005;54(RR-17):1-141.

3. Walsh BK, Betit P, Fink JB, Pereira LM, Arnold J. Characterization of ribavirin aerosol with small particle aerosol generator and vibrating mesh micropump aerosol technologies. Respir Care 2016;61(5):577585.

4. Wilkes AR. The effect of gas flow on the filtration performance of breathing system filters. Anaesthesia 2004;59(3):278-282. 